\title{
Non-coding transcription characterization and annotation
}

\section{A guide and web resource for non-coding RNA databases}

\author{
Alexandre Rossi Paschoal, ${ }^{3,5,+}$ Vinicius Maracaja-Coutinho, ${ }^{2,5,+}$ João Carlos Setubal, ${ }^{2}$ Zilá Luz Paulino Simões, ${ }^{4}$ \\ Sergio Verjovski-Almeida ${ }^{2}$ and Alan Mitchell Durham ${ }^{1, *}$
}

\begin{abstract}
'Departamento de Ciência da Computação; Instituto de Matemática e Estatística; Universidade de São Paulo; São Paulo, Brazil; ${ }^{2}$ Departamento de Bioquímica; Instituto de Química; Universidade de São Paulo; São Paulo, Brazil; ${ }^{3}$ Engenharia da Computação; Universidade Tecnológica Federal do Paraná - Campus Cornélio Procópio; Cornélio Procópio, Brazil; ${ }^{4}$ Departamento de Biologia; Faculdade de Filosofia Ciências e Letras de Ribeirão Preto; Universidade de São Paulo; São Paulo, Brazil; ${ }^{5}$ Programa Interunidades em Bioinformática; Instituto de Matemática e Estatística; Universidade de São Paulo; São Paulo, Brazil
\end{abstract}

${ }^{\dagger}$ Authors contributed equally to this work.

Keywords: ncRNA, non-coding RNA, database, transcription, bioinformatics, web tool

Abbreviations: ncRNA, non-coding RNA; lincRNA, long intergenic non-coding RNA; lncRNA, long non-coding RNA; nt, nucleotide; HGNC, The HUGO Gene Nomenclature Committee; CNE, conserved non-coding elements;

NAT, natural antisense transcript; tRNA, transfer RNA; rRNA, ribosomal RNA; mRNA, messenger RNA; miRNA, microRNA; snoRNA, small nucleolar RNA; siRNA, small interfering RNA; SRP RNA, signal recognition particle RNA; piRNA, piwi-interacting RNA; TERC, telomerase RNA component

Large-scale transcriptome projects have shown that the number of RNA transcripts not coding for proteins (noncoding RNAs) is much larger than previously recognized. High-throughput technologies, coupled with bioinformatics approaches, have produced increasing amounts of data, highlighting the role of non-coding RNAs (ncRNAs) in biological processes. Data generated by these studies include diverse non-coding RNA classes from organisms of different kingdoms, which were obtained using different experimental and computational assays. This has led to a rapid increase of specialized RNA databases. The fast growth in the number of available databases makes integration of stored information a difficult task. We present here NRDR, a Non-coding RNA Databases Resource for information retrieval on ncRNA databases (www.ncrnadatabases.org). We performed a survey of 102 public databases on ncRNAs and we have introduced four categorizations to classify these databases and to help researchers quickly search and find the information they need: RNA family, information source, information content and available search mechanisms. NRDR is a useful databases searching tool that will facilitate research on ncRNAs.

\section{Introduction}

High-throughput technologies such as tiling arrays or deep sequencing, ${ }^{1-4}$ combined with a large number of bioinformatics approaches, ${ }^{5-8}$ have produced increasing amounts of expression

*Correspondence to: Alan Mitchell Durham; Email: aland@usp.br Submitted: 11/22/11; Revised: 01/11/12; Accepted: 01/13/12 http://dx.doi.org/10.4161/rna.19352 data and functional information related to the characterization of non-coding RNAs (ncRNAs). Presently, there are over 100 public databases with ncRNA information, which cover a wide range of ncRNA families. These databases have information on secondary structure of RNAs, on tissues where they are expressed, on expression conditions, on specific species, on functional annotation, phylogeny, taxonomy and alignment analysis, on putative target genes, on related diseases, and other information. These databases can be searched using a wide range of different methods such as sequence similarity search, keyword or tag search, manual browsing of tables, genomic alignment coordinates and genomic location in relation to a given locus with clustered transcripts.

Given this multitude of databases it is clear that some sort of metaresource, providing a single point-of-entry for search and classification of the information, is needed. In this work we present the Non-coding RNA Databases Resource (NRDR), which is a web portal that indexes currently available public databases with non-coding RNA information in a user-friendly way. NRDR allows users to quickly find databases using criteria based on RNA family, information source, information content and other available search mechanisms.

The importance of a publicly available portal for searching information on ncRNAs has been highlighted by a recent publication. ${ }^{9}$ It must be noted that Bateman et al. ${ }^{9}$ argue for a central repository of ncRNA information and calls for the formation of a consortium with this goal. NRDR is not a central repository, since it does not store any ncRNA information. In addition, NRDR does not index databases that are specific for tRNAs and rRNAs. Nevertheless, by currently indexing 102 ncRNA databases, we believe that NRDR is a useful tool that will facilitate research on ncRNAs. 
NRDR overview. NRDR can be accessed at www. ncrnadatabases.org. The website includes a description of each indexed database and a link to the respective website. The complete list and full description for each database can also be found on the Supplementary Material. NRDR is updated every six months, driven by manual curation of literature.

NRDR provides a search interface where users can retrieve a list of databases filtered by user-defined criteria. Free-text boxes are available for a combined search where multiple keywords can be applied. As an example, the user can filter the data using an RNA class name, database name, organism name or PubMed ID (e.g., microRNA, Homo sapiens, ID number). Additionally, the user can select only databases that have data sets available for downloading, or those with a Graphic Genome View available (e.g., Genome Browser). For a more comprehensive search, there is a provision for the user to search directly by the keywords that appear in the text description of each database (e.g., "intergenic," "transcription" and "networks"). Finally, it is also possible to explore the NRDR data by browsing it according to the organism of interest. Figure 1 shows the NRDR search page and an example of a database description retrieved from our server.

Databases indexed by NRDR were manually classified using four criteria:

(1) RNA families: what classes of ncRNAs are present in a database?

(2) Information source: what is the provenance of the ncRNA information? (from experimental evidence; from computational analysis only; from manual curation of information obtained experimentally and/or computationally; and from literature).

(3) Information content: what are the various types of information stored in a database (e.g., sequence, annotation, expression)?
(4) Search mechanisms: What search mechanisms are available in a database?

NRDR automatically generates statistics on how the databases are distributed according to each classification criterion. These statistics are available on the NRDR web resource (see statistics link) and were used below to provide an overview of current work on ncRNA research.

RNA families: different classes of transcripts are present in databases. A challenge in the annotation of novel ncRNAs is to categorize them into well-defined classes. Currently, most of the specific ncRNA families are defined by the structural molecular folding, ${ }^{10,11}$ assuming that transcripts with a common structural conformation act in a similar functional manner in cellular processes. Sequence similarity is a very important tool to classify new ncRNAs, but limits the effectiveness of characterizing more divergent sequences. ${ }^{11}$

Reflecting the limited amount of specific functional data, the complex sets of short and long ncRNAs being detected by highthroughput expression technologies have been simply annotated in databases as "small RNAs"12,13, including all RNA sequences shorter than $200 \mathrm{nt}$, or "long RNAs"14 (>200 nt), with little information about which functional class or family they belong to.

Recently, these difficulties prompted a standardization proposed by the HUGO Gene Nomenclature Committee (HGNC), the sole organization authorized to assign nomenclature to human transcripts. ${ }^{15}$ They classified these long transcripts as a large class named long non-coding RNAs (lncRNAs), which is subdivided into two main classes: (1) transcripts with known function (e.g., XIST or HOTAIR), and (2) those with unknown functional annotation, which are sub-classified according to their genomic location, such as: intronic (IT), antisense (AS), intergenic (LINC) or host transcripts of other small ncRNAs. ${ }^{15}$ Under the present categorization, termed as an ongoing project by

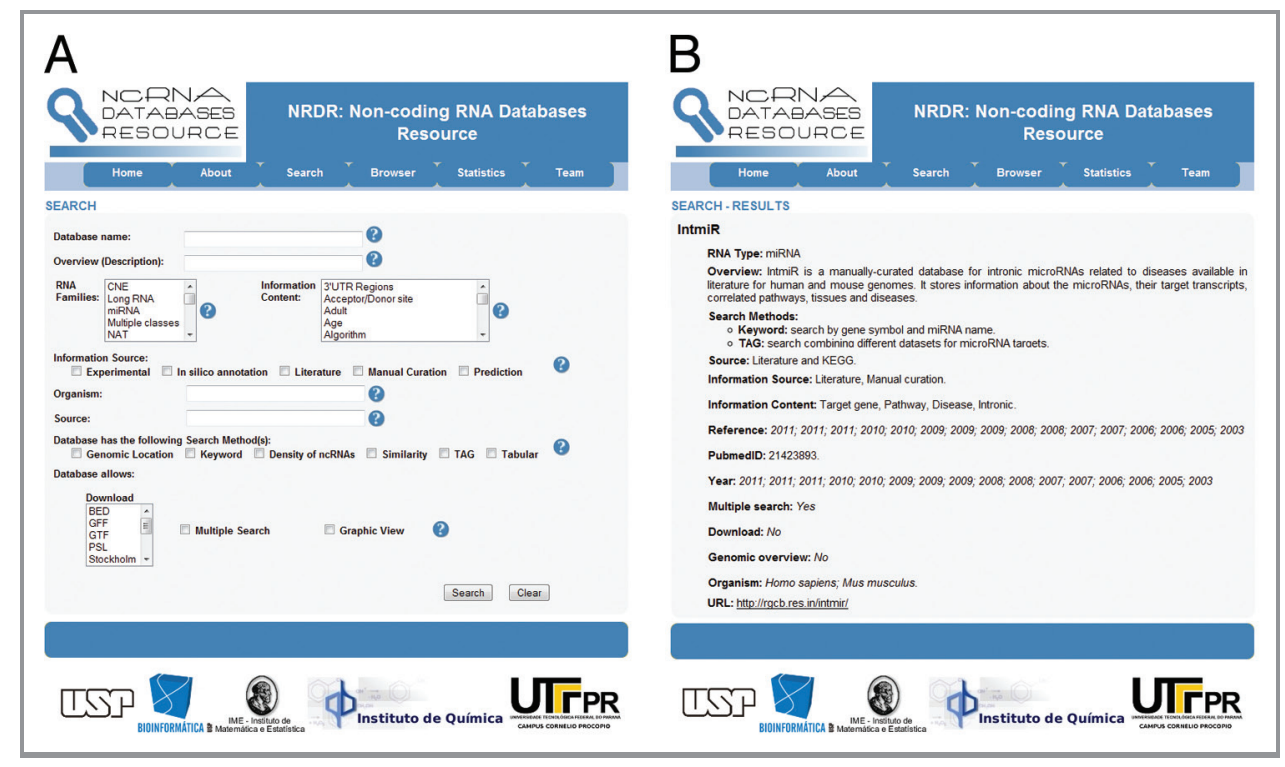

Figure 1. Overview of our non-coding RNA Databases Resource (NRDR) web tool. (A) Initial screen showing the different types of search that a user can perform. (B) Example of a database description, from one of the databases that were listed in the output results, which satisfied the search criteria shown in (A). The actual output results screen from the search (not shown) is a list of databases with links to their respective descriptions, available in NRDR. 
HGNC, these lncRNAs were described as spliced, capped and polyadenylated RNAs, ${ }^{15}$ which clearly does not encompass all different lncRNAs that may be unspliced and/or nonpolyadenylated. ${ }^{16-18}$

Due to all the difficulties in categorizing RNAs, in NRDR we chose to group them according to the different classes of RNAs used in the databases themselves, combined whenever possible with HGNC nomenclature, as exemplified below. Databases that are not specific for a single RNA class, such as RFAM $^{10}$ ncRNAdb $^{19}$ and NONCODE ${ }^{20}$ were classified as containing multiple classes. Apart from those ncRNAs categorized by HGNC, other classes of ncRNAs are present in databases, such as: conserved non-coding elements (CNEs), some of which are associated with well-conserved non-coding transcripts; ${ }^{21,22}$ structured RNAs that were usually predicted by molecular structural folding algorithms applied to transcriptomic or genomic sequences; ${ }^{23} m R N A$-like RNAs, long spliced non-coding transcripts; ${ }^{24,25}$ and Natural Antisense Transcripts (NATs), long transcripts that are partially complementary to other endogenous RNAs. ${ }^{26-28}$

Figure 2 presents the number of published databases related to ncRNAs over the years. It shows a substantial increase in the number of repositories available after 2005. The 102 surveyed databases were categorized by the classes of ncRNAs they contain (Table 1 , see the statistics page of the web resource). The distribution of databases per ncRNA class is presented in Figure 3. Some particularities were observed among the 102 databases. The majority of databases (73 of 102) host small RNAs, with $68 \%$ of them (50 of 73) related specifically to microRNAs. In 2010, Kozomara and Griffiths-Jones highlighted that in the previous three years the number of miRNA sequences in the miRBase database had almost tripled. ${ }^{29}$ This reflects the high interest of the research community in microRNAs. This interest is not new, and is due to the role these molecules play in regulating gene translation, and also probably because microRNAs have been correlated with different pathologies, diseases and with the development process. ${ }^{30-32}$

Although there are in the literature some well-known functionally annotated long ncRNAs, such as XIST ${ }^{33}{ }^{33}$ HTAIR $^{34}$ and $M A L A T 1,{ }^{35}$ their presence in databases is still scarce when compared with small RNAs (there are only five databases specific to long ncRNAs $\left.{ }^{14,26-28,36}\right)$. Currently there are eight databases

\section{Small RNAs}

TERC

Long RNAs

Other

CNE

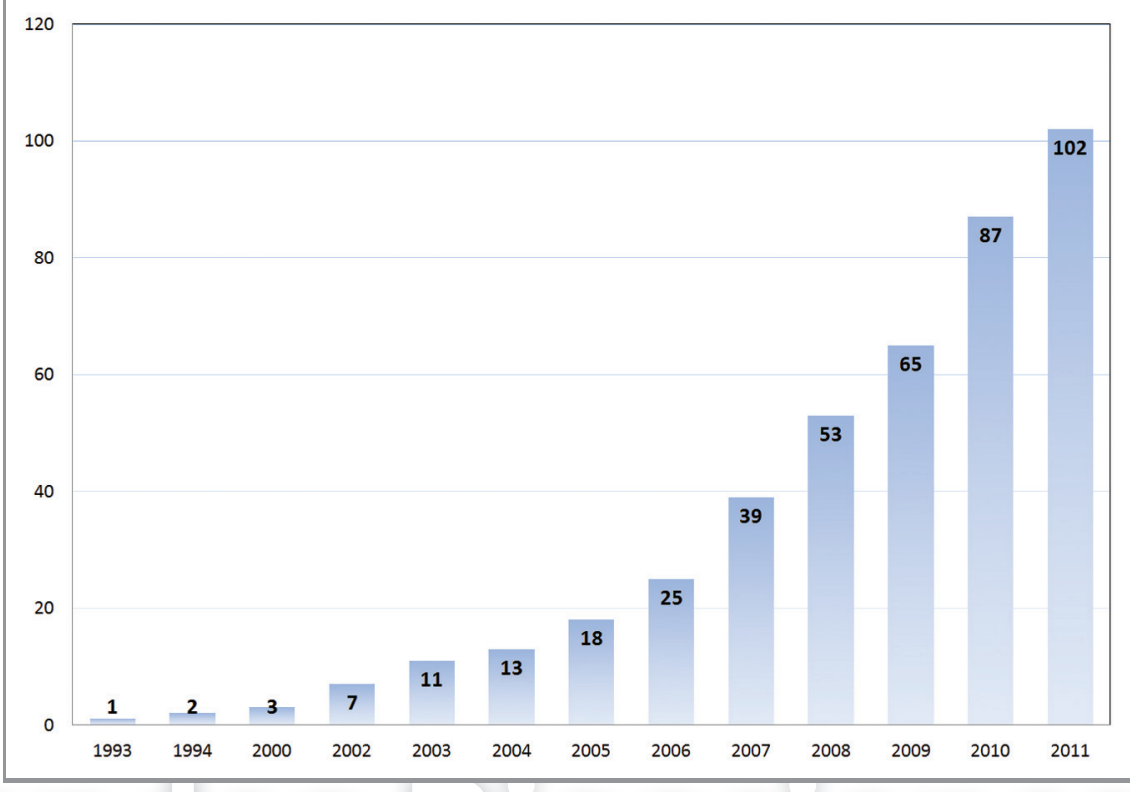

Figure 2. Publication of ncRNA databases over the years. Values for 2011 were computed until November of that year.

Table 1. Different RNA classes listed in the databases. Whenever possible we tried to associate the ncRNAs described on databases with HGCN classification

RNA class Description

snoRNAs small nucleolar RNAs (e.g., CD and H/ACA box)

small RNAs small RNAs ( $<200$ nucleotides) that can include classes not yet classified by HGNC

siRNAs small interfering RNAs

miRNAs microRNAs

SRP RNAs Signal recognition particle RNA

piRNAs piwi-interacting RNAs

Ribozymes Rnase P and group I, II and III intronic RNAs removed in the splicing process or involved in RNA catalyzes

Telomerase RNA component

long ncRNAs Long RNAs ( $>200$ nucleotides), that can include classes not yet classified by HGNC

NATs Natural antisense transcripts, complementary to other RNAs

Multiple classes Not specific to a unique class of RNA, which means there is a diversity of RNA families

Conserved non-coding elements

Structured RNAs Specific to structured RNAs (e.g., secondary structure or 3D structure)

with data originated from next generation sequencing technologies, ${ }^{12,13,24,37-40}$ however only one of them (ncRNAimprint ${ }^{24}$ ) is related to long RNAs (e.g., antisense long RNAs and mRNA-like RNAs). Increasing attention has been given in the past five years to long ncRNAs, which reflects the intensive use of large-scale 


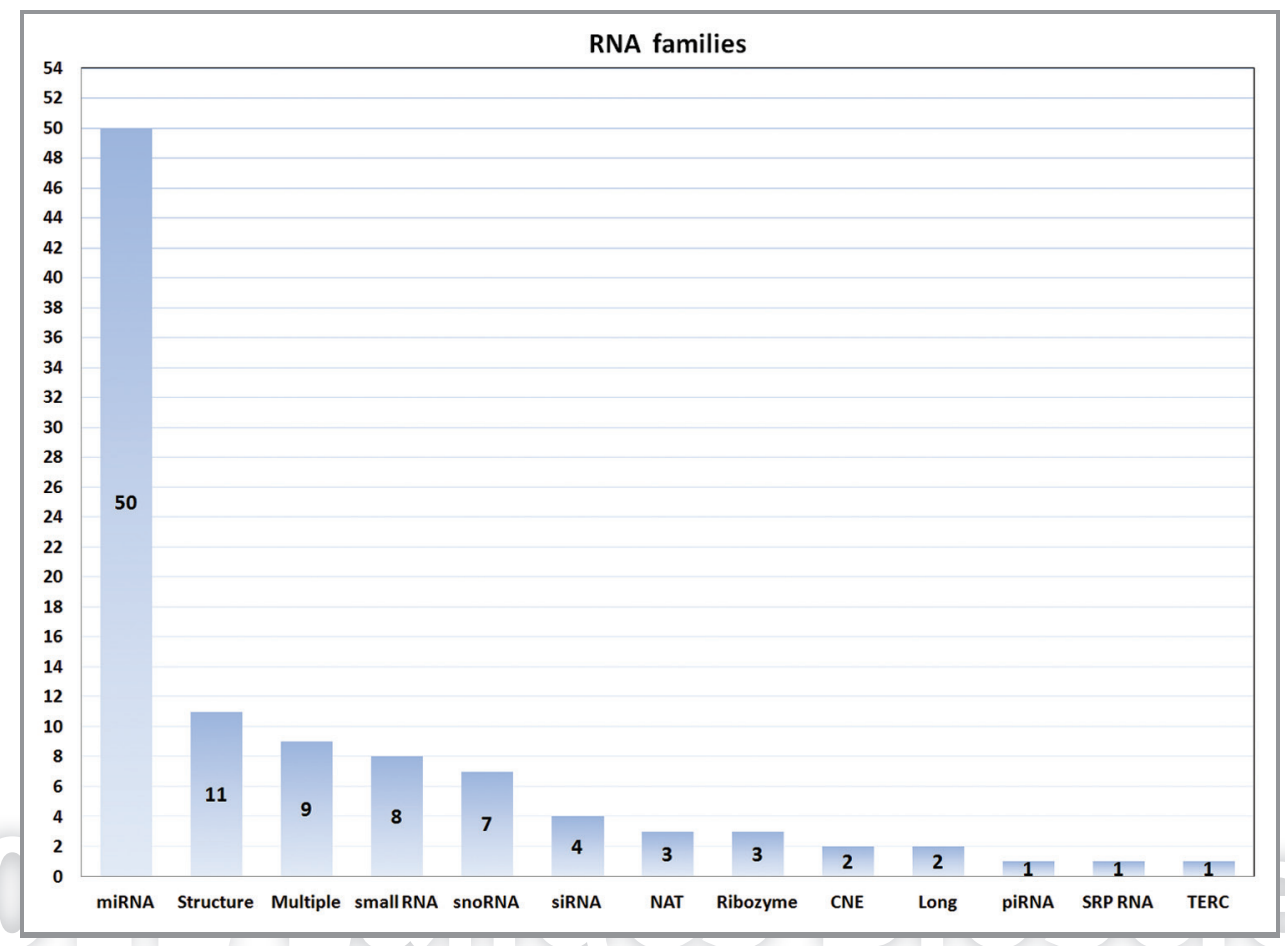

Figure 3. Database distribution per RNA class.

technologies for expression measurements ${ }^{1,16,41}$ and the recognition that altered expression of long ncRNAs is present in many diseases such as different types of human cancer. ${ }^{42-44}$ Nevertheless, only a very small fraction of such functional data are present in ncRNA databases. For example, transcription has been analyzed by ultra-dense tiling arrays covering the entire $H O X$ gene loci, and HOTAIR has been identified along with another 170 long ncRNAs as being differentially expressed among normal human breast epithelia, primary breast carcinomas, and distant metastases. ${ }^{34}$ Except for HOTAIR itself, none of the dozens of long ncRNAs differentially expressed in the $H O X$ loci and related to breast cancer ${ }^{34}$ are present for example in the $\operatorname{lncRNAdb}{ }^{36}$ or in the NONCODE database, a large repository of ncRNAs which has been recently updated to include an integrative annotation of long non-coding RNAs. ${ }^{20}$ Similarly, microarray analysis revealed expression profiles comprised of dozens of long ncRNAs correlated with a number of different types of cancer. ${ }^{45-49}$ Again, none of these ncRNAs are in the databases, possibly reflecting the lack of uniform and systematic annotation nomenclature for the diverse and extensive amount of long ncRNAs expressed in human tissues. In another example, a recent paper using targeted RNA sequencing for an in-depth analysis of the human transcriptome reveals multiple additional isoforms of coding and non-coding genes; ${ }^{50}$ similar results had been previously shown by tiling arrays. ${ }^{51}$ Also, very long ncRNAs abundantly transcribed in intergenic genomic regions have been identified recently, and expression of these regions was shown to be associated with neoplastic transformation. ${ }^{52}$ Again, none of these data are present in any database. Collectively, these results reveal that the range, depth and complexity of the human transcriptome is far from fully characterized, ${ }^{50}$ and at the same time they point to a considerable limitation regarding the completeness of any database related to long ncRNAs.

Information source: the reliability of stored data. Information stored in these databases comes from different sources. We associate databases to four types of information source: (1) in silico annotation, where ncRNAs are characterized locally by computational analyses, (2) literature, where data are extracted from published articles, (3) manual curation, where information is locally validated by a human expert and (4) experimental information, derived directly from biological assays. Of these, experimental information is generally the most reliable source. Figure 4 shows the distribution of databases per information source. This information can be easily retrieved on our web tool.

Experimental data on ncRNAs is present in 67 of the 102 databases. This information could be used as a validation catalog for laboratory experiments, as well as for testing and developing new approaches in computational biology. However, just 40 of these make the data available for downloading (see Supplemental Tables for a complete list, or the Statistics page of the web resource), of which only 24 offer the data directly in FASTA format or similar sequence file. NRDR can quickly guide the investigator to the databases providing a given downloadable format of interest (e.g., BED, GFF or PSL).

Information content: information stored in public domain databases. Information content describes the various types of information stored in the databases, such as sequence, annotation, expression. This is not always clearly stated in the database name and sometimes not even in the homepage; for this reason, each database was manually examined and a number of terms (usually 


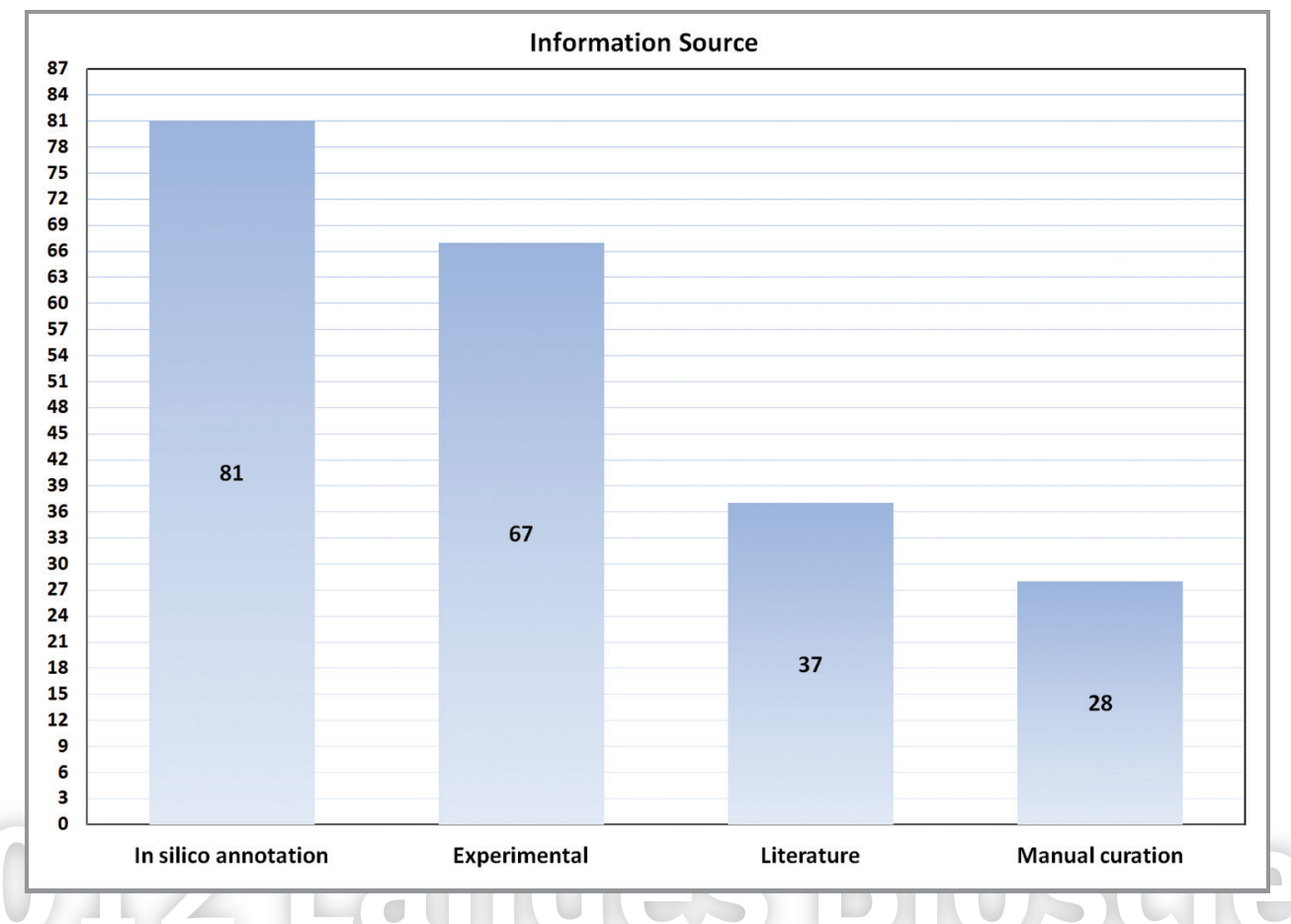

Figure 4. Database distribution per information source.

from 9 to 19 terms) were associated to that database, out of a list with 257 terms that we have generated from all terms present in the databases. The statistics link at the NRDR portal contains the list of all generated terms along with the number of databases that were associated to each given term; in addition, upon accessing the NRDR description of each database, one can see the list of all terms that have been associated to that database under the information content category. In the search link of the portal the databases can be searched by information content using multiple combinations of terms; in addition, a search for sequence under information content can be combined with a filter that discriminates the databases according to the sequence formats available for download (FASTA, GFF, BED, PSL, etc.). In Figure 5, we grouped and ranked the top 10 most frequent terms associated to the databases.

Browsing the information stored in databases, one can get a general idea of the results of ncRNA research that are finding their way into public databases. There is a large number of databases containing information related to expression (38 out of 102), in comparison to the scarce information related to interaction of these non-coding transcripts with other biomolecules (DNA, RNA, or protein). There are only nine databases with information on molecular interactions. ${ }^{53-61}$ Most of these annotations are related to interaction between ncRNA and their target transcripts in an RNA:RNA relationship; little information is available covering RNA:protein or RNA:DNA relationships. Discovering new functional mechanisms of these molecules is a big challenge, which is crucial for understanding the functionality of these ubiquitous transcripts in eukaryotic genomes. Despite evidence pointing to the functionality of ncRNAs, such as: (1) tissue specificity; ${ }^{62}$ (2) involvement in disease; ${ }^{43,45}$ (3) development; ${ }^{63}$ (4) genomic imprinting; ${ }^{64}$ (5) alternative splicing regulation; ${ }^{65}$ there is still limited evidence of their mechanisms of action, and besides the miRNAs, only a few other ncRNAs are annotated in the databases as functionally characterized.

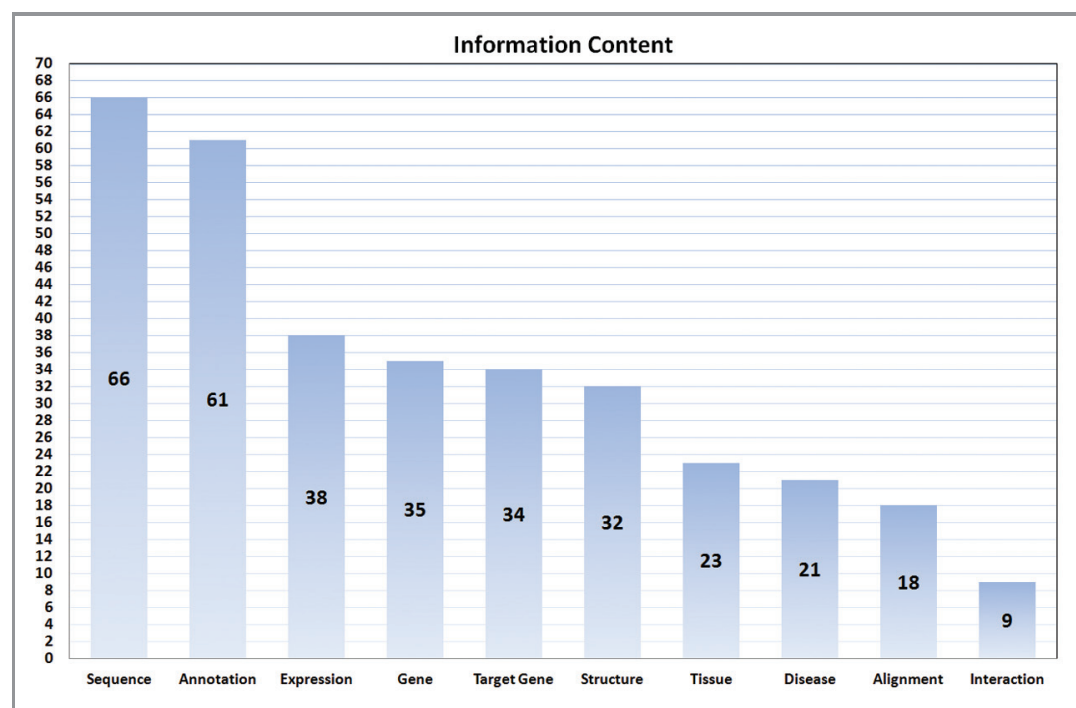

Figure 5. Top ten ranking of information content terms based on the information stored in the databases. 
Examples of transcripts with known mechanisms of action that are present in databases such as $\operatorname{lncRNAdb}{ }^{36}$ and NONCODE ${ }^{20}$ include: (1) HOTAIR, a long intergenic ncRNA located within the $H O X C$ gene cluster that regulates the chromatin state in the HOXD locus after binding to PRC2 Polycomb repressor complex $^{66}$ and to LSD1, a histone lysine demethylase, ${ }^{67}$ leading to gene-silencing of the HOXD gene cluster; (2) p21, a p53responsive long intergenic transcript, that binds to hnRNP-K protein and mediates global gene repression and apoptosis in the p53 pathway; ${ }^{68}$ and (3) BC1 (Brain Cytoplasmic RNA 1), a neuronal small ncRNA that interacts with eukaryotic initiation factor 4 (eIF4), resulting in a subsequent translational repression. ${ }^{69}$ These transcripts and a few others serve as paradigms of molecular mechanisms of ncRNAs ${ }^{70}$ acting in the cellular processes fine-tuning regulation. Biological knowledge acquired with the characterization of these ncRNAs could guide the development of new experimental and computational approaches to characterize the immense repertoire of small and long ncRNAs without well-defined biological mechanisms of action, which should feed the ncRNA databases in the coming years.

Recently, a number of databases involving systems biology approaches have been described. ${ }^{71-78}$ These databases, which are indexed by NRDR, integrate data sets of regulation (e.g., transcription factor binding sites, or epigenetic markers), expression, target genes and putative regulated networks and pathways. However, there is still a lack of data integrating these transcripts with proteins.

Search mechanisms: extracting information from databases. Information of interest from ncRNA databases can be located using different search mechanisms. We have grouped the search mechanisms into six categories: similarity, keyword, tag, genomic location, tabular and density of ncRNAs (Fig. 6). In some databases these options can be used together. Depending on the prior knowledge one has about the RNA of interest (e.g., nucleotide sequence, gene locus name in which it is inserted or associated disease), it is important to choose the databases with appropriate search mechanisms that can provide the necessary information retrieval capabilities.

Of all the search mechanisms, the keyword and tag options are the most common ways to search information in ncRNA databases (Fig. 6), being also the simplest ones. The keyword option consists of a text box that accepts free text (e.g., accession code, gene name, Ensembl accession, GO accession, etc.). The tag option consists of a pre-defined list of terms (e.g., tissue or cell line names, organism, clade) usually in a pull-down menu.

Similarity search is the third most common mechanism, available in 32 databases (Fig. 6). The BLAST program ${ }^{79}$ is used for this purpose in the majority of the databases. Similarity search alone has the drawback that ncRNA families can be very divergent in primary sequence, conserving only their secondary structure. ${ }^{80}$ Only the Rfam database ${ }^{10}$ considers structural information in the search, and even so it is still associated with a pre-processing by a low stringency similarity search.

Only 14 databases offer search by genomic coordinates (Fig. 6), where ncRNAs are retrieved based on intervals of positions in the genome. This search helps the examination of specific regions of interest in a genome, and is extremely useful to explore different pre-aligned data sets in the vicinities of a given ncRNA of interest. An example of the use of such a query is the investigation of putative regulatory signals (e.g., $\mathrm{CpG}$ islands, transcription

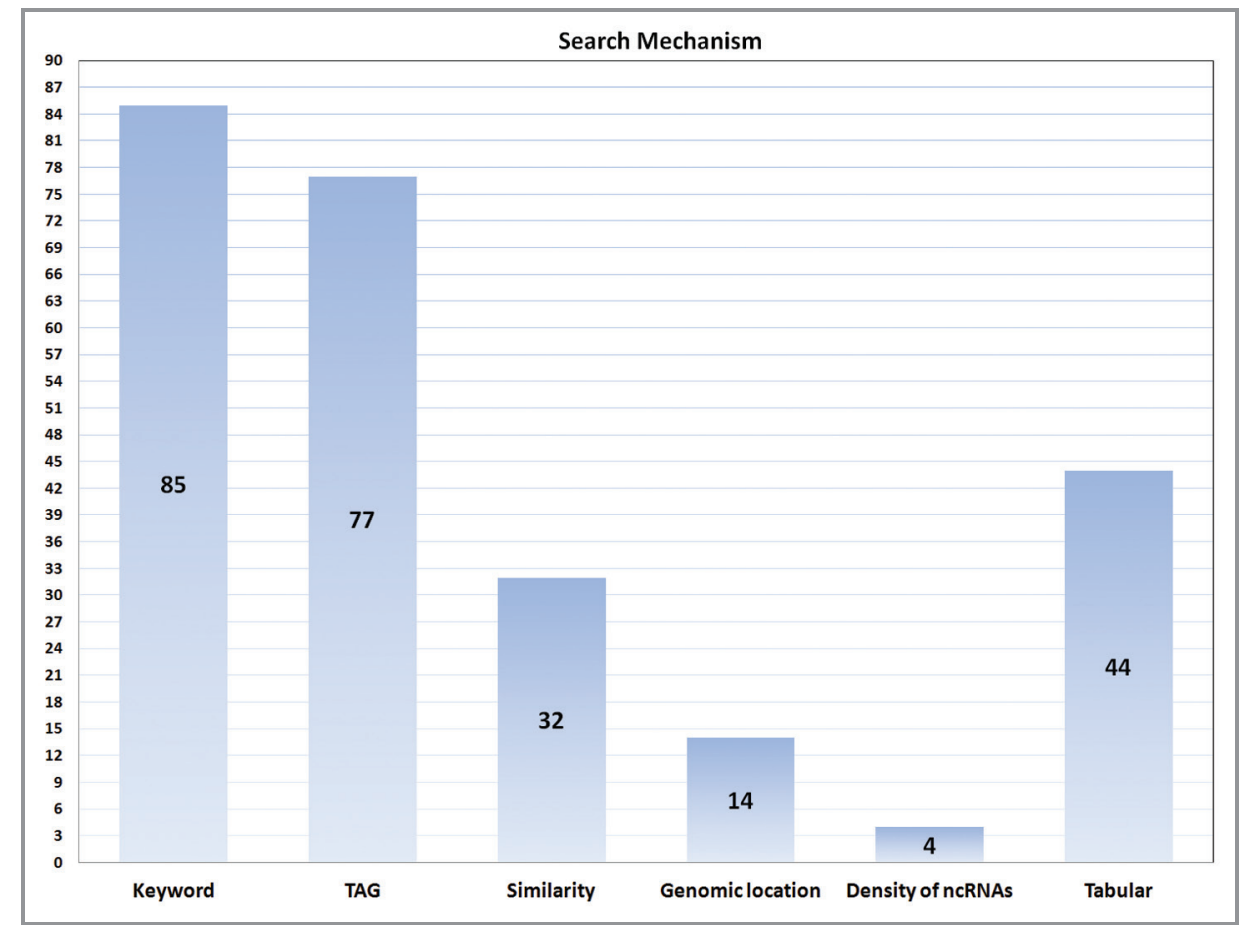

Figure 6. Database distribution per search mechanism. 
factor binding sites, epigenetic modification markers) mapping to the genome near the ncRNA sequence of interest.

The density of ncRNAs search option is a variation of the search by genomic location, with the goal of determining a genomic region by the density of RNAs that are clustered in that region. This search can be useful to identify clusters of transcripts (especially of miRNAs) that could be originated from multiple transcriptional units in a given genomic locus.

The last search mechanism is the tabular form (as a table or list). Here, the links available in the databases' webpages lead to tables listing the information. Search is performed by manually browsing these tables.

\section{Conclusion and Perspectives}

The explosion in sequence information spurred by new sequencing technologies has created in turn an abundance of ncRNA online databases. NRDR is an attempt to facilitate information discovery as available in these databases. With the rate of sequencing projects continuing to increase we can expect that some of the existing databases will vastly increase their contents in terms of sequence data, while new specialized databases will also continue to be created. NRDR was designed in such a way that new online resources can easily be added, thus allowing NRDR to keep pace with new developments.

\section{Acknowledgments}

This work was funded in part by grants from Conselho Nacional de Desenvolvimento Científico e Tecnológico (CNPq) to A.M.D.; and from CNPq, Fundação de Amparo a Pesquisa do Estado de São Paulo (FAPESP), Financiadora de Estudos e Projetos (FINEP) and the FP-7 European Community SEtTReND grant agreement number 241865 to S.V.A. A.R.P. received a fellowship from CAPES; VMC received a fellowship from CAPES and subsequently from FAPESP. S.V.A. received an established investigator fellowship award from CNPq.

\section{Supplemental Material}

Supplemental materials may be found here: www.landesbioscience.com/journals/rnabiology/article/19352

\section{References}

1. Kapranov P, Cheng J, Dike S, Nix DA, Duttagupta R, Willingham AT, et al. RNA maps reveal new RNA classes and a possible function for pervasive transcription. Science 2007; 316:1484-8; PMID:17510325; http://dx.doi.org/10.1126/science.1138341

2. Guffanti A, Iacono M, Pelucchi P, Kim N, Soldà G, Croft LJ, et al. A transcriptional sketch of a primary human breast cancer by 454 deep sequencing. BMC Genomics 2009; 10:163; PMID:19379481; http://dx. doi.org/10.1186/1471-2164-10-163

3. Vockenhuber MP, Sharma CM, Statt MG, Schmidt D, $\mathrm{Xu} Z$, Dietrich $S$, et al. Deep sequencing-based identification of small non-coding RNAs in Streptomyces coelicolor. RNA Biol 2011; 8:468-77; PMID: 21521948; http://dx.doi.org/10.4161/rna.8.3.14421

4. Ling KH, Brautigan PJ, Hahn CN, Daish T, Rayner JR, Cheah PS, et al. Deep sequencing analysis of the developing mouse brain reveals a novel microRNA. BMC Genomics 2011; 12:176; PMID:21466694; http://dx.doi.org/10.1186/1471-2164-12-176

5. Backofen R, Bernhart SH, Flamm C, Fried C, Fritzsch G, Hackermüller J, et al. Athanasius F Bompfünewerer Consortium. RNAs everywhere: genome-wide annotation of structured RNAs. J Exp Zool B Mol Dev Evol 2007; 308:1-25; PMID:17171697

6. Jossinet F, Ludwig TE, Westhof E. RNA structure: bioinformatic analysis. Curr Opin Microbiol 2007; 10: 279-85; PMID:17548241; http://dx.doi.org/10.1016/ j.mib.2007.05.010

7. Machado-Lima A, del Portillo HA, Durham AM. Computational methods in noncoding RNA research. J Math Biol 2008; 56:15-49; PMID:17786447; http:// dx.doi.org/10.1007/s00285-007-0122-6

8. Soldà G, Makunin IV, Sezerman OU, Corradin A, Corti G, Guffanti A. An Ariadne's thread to the identification and annotation of noncoding RNAs in eukaryotes. Brief Bioinform 2009; 10:475-89; PMID: 19383843; http://dx.doi.org/10.1093/bib/bbp022

9. Bateman A, Agrawal S, Birney E, Bruford EA, Bujnicki JM, Cochrane G, et al. RNAcentral: A vision for an international database of RNA sequences. RNA 2011; 17:1941-6; PMID:21940779; http://dx.doi.org/10.1261/ rna.2750811
10. Gardner PP, Daub J, Tate JG, Nawrocki EP, Kolbe DL, Lindgreen S, et al. Rfam: updates to the RNA families database. Nucleic Acids Res 2009; 37(Database issue): D136-40; PMID:18953034; http://dx.doi.org/10.1093/ nar/gkn766

11. Will S, Reiche K, Hofacker IL, Stadler PF, Backofen R. Inferring noncoding RNA families and classes by means of genome-scale structure-based clustering. PLoS Comput Biol 2007; 3:e65; PMID:17432929; http://dx.doi.org/10. 1371/journal.pcbi.0030065

12. Yang JH, Shao P, Zhou H, Chen YQ, Qu LH. deepBase: a database for deeply annotating and mining deep sequencing data. Nucleic Acids Res 2010; 38(Database issue):D123-30; PMID:19966272; http://dx.doi.org/10.1093/nar/gkp943

13. Johnson C, Bowman L, Adai AT, Vance V, Sundaresan V. CSRDB: a small RNA integrated database and browser resource for cereals. Nucleic Acids Res 2007; 35(Database issue):D829-33; PMID:17169981; http:// dx.doi.org/10.1093/nar/gkl991

14. Dinger ME, Pang KC, Mercer TR, Crowe ML, Grimmond SM, Mattick JS. NRED: a database of long noncoding RNA expression. Nucleic Acids Res 2009; 37(Database issue):D122-6; PMID:18829717; http://dx.doi.org/10.1093/nar/gkn617

15. Wright MW, Bruford EA. Naming 'junk': human nonprotein coding RNA (ncRNA) gene nomenclature. Hum Genomics 2011; 5:90-8; PMID:21296742

16. Nakaya HI, Amaral PP, Louro R, Lopes A, Fachel AA, Moreira YB, et al. Genome mapping and expression analyses of human intronic noncoding RNAs reveal tissue-specific patterns and enrichment in genes related to regulation of transcription. Genome Biol 2007; 8: R43; PMID:17386095; http://dx.doi.org/10.1186/gb2007-8-3-r43

17. Louro R, El-Jundi T, Nakaya HI, Reis EM, VerjovskiAlmeida S. Conserved tissue expression signatures of intronic noncoding RNAs transcribed from human and mouse loci. Genomics 2008; 92:18-25; PMID: 18495418; http://dx.doi.org/10.1016/j.ygeno.2008.03. 013
18. Yang L, Duff MO, Graveley BR, Carmichael GG Chen LL. Genomewide characterization of nonpolyadenylated RNAs. Genome Biol 2011; 12:R16; PMID:21324177; http://dx.doi.org/10.1186/gb-2011 12-2-r16

19. Szymanski M, Erdmann VA, Barciszewski J. Noncoding RNAs database (ncRNAdb). Nucleic Acids Res 2007; 35(Database issue):D162-4; PMID: 17169980; http://dx.doi.org/10.1093/nar/gkl994

20. Bu D, Yu K, Sun S, Xie C, Skogerbø G, Miao R, et al. NONCODE v3.0: integrative annotation of long noncoding RNAs. Nucleic Acids Res 2012; 40(Database issue):D210-5; PMID:22135294; http://dx.doi.org/10. 1093/nar/gkr1175

21. Woolfe A, Goode DK, Cooke J, Callaway H, Smith S, Snell P, et al. CONDOR: a database resource of developmentally associated conserved non-coding elements. BMC Dev Biol 2007; 7:100; PMID:17760977; http:// dx.doi.org/10.1186/1471-213X-7-100

22. Lee AP, Yang Y, Brenner S, Venkatesh B. TFCONES: a database of vertebrate transcription factor-encoding genes and their associated conserved noncoding elements. BMC Genomics 2007; 8:441; PMID:18045502; http://dx.doi.org/10.1186/1471-2164-8-441

23. Washietl S, Pedersen JS, Korbel JO, Stocsits C, Gruber AR, Hackermüller J, et al. Structured RNAs in the ENCODE selected regions of the human genome. Genome Res 2007; 17:852-64; PMID:17568003; http://dx.doi.org/10.1101/gr.5650707

24. Zhang Y, Guan DG, Yang JH, Shao P, Zhou H, Qu LH. ncRNAimprint: a comprehensive database of mammalian imprinted noncoding RNAs. RNA 2010; 16:1889-901; PMID:20801769; http://dx.doi.org/10. 1261/rna.2226910

25. Sone M, Hayashi T, Tarui H, Agata K, Takeichi M, Nakagawa S. The mRNA-like noncoding RNA Gomafu constitutes a novel nuclear domain in a subset of neurons. J Cell Sci 2007; 120:2498-506; PMID: 17623775; http://dx.doi.org/10.1242/jcs.009357 
26. Yin Y, Zhao Y, Wang J, Liu C, Chen S, Chen R, et al. antiCODE: a natural sense-antisense transcripts database. BMC Bioinformatics 2007; 8:319; PMID:17760969; http://dx.doi.org/10.1186/1471-2105-8-319

27. Zhang Y, Li J, Kong L, Gao G, Liu QR, Wei L. NATsDB: Natural Antisense Transcripts DataBase. Nucleic Acids Res 2007; 35(Database issue):D156-61; PMID:17082204; http://dx.doi.org/10.1093/nar/gkl782

28. Li JT, Zhang Y, Kong L, Liu QR, Wei L. Trans-natural antisense transcripts including noncoding RNAs in 10 species: implications for expression regulation. Nucleic Acids Res 2008; 36:4833-44; PMID:18653530; http:// dx.doi.org/10.1093/nar/gkn470

29. Kozomara A, Griffiths-Jones S. miRBase: integrating microRNA annotation and deep-sequencing data. Nucleic Acids Res 2011; 39(Database issue):D1527; PMID:21037258; http://dx.doi.org/10.1093/nar/ gkq1027

30. Davis-Dusenbery BN, Hata A. Mechanisms of control of microRNA biogenesis. J Biochem 2010; 148:38192; PMID:20833630

31. Nicolas FE, Lopez-Martinez AF. MicroRNAs in human diseases. Recent Pat DNA Gene Seq 2010; 4:142-54; PMID:21288192; http://dx.doi.org/10.2174/ 187221510794751659

32. Silahtaroglu A, Stenvang J. MicroRNAs, epigenetics and disease. Essays Biochem 2010; 48:165-85; PMID: 20822493; http://dx.doi.org/10.1042/bse0480165

33. Plath K, Mlynarczyk-Evans S, Nusinow DA, Panning B. Xist RNA and the mechanism of X chromosome inactivation. Annu Rev Genet 2002; 36:233-78; PMID:12429693; http://dx.doi.org/10.1146/annurev. genet.36.042902.092433

34. Gupta RA, Shah N, Wang KC, Kim J, Horlings HM, Wong DJ, et al. Long non-coding RNA HOTAIR reprograms chromatin state to promote cancer metastasis. Nature 2010; 464:1071-6; PMID:20393566; http://dx.doi.org/10.1038/nature08975

35. Ji P, Diederichs S, Wang W, Böing S, Metzger R, Schneider PM, et al. MALAT-1, a novel noncoding RNA, and thymosin beta4 predict metastasis and survival in early-stage non-small cell lung cancer. Oncogene 2003; 22:8031-41; PMID:12970751; http://dx.doi.org/10. 1038/sj.onc. 1206928

36. Amaral PP, Clark MB, Gascoigne DK, Dinger ME, Mattick JS. IncRNAdb: a reference database for long noncoding RNAs. Nucleic Acids Res 2011; 39(Database issue):D146-51; PMID:21112873; http:// dx.doi.org/10.1093/nar/gkq1138

37. Yang JH, Li JH, Shao P, Zhou H, Chen YQ, Qu LH. starBase: a database for exploring microRNA-mRNA interaction maps from Argonaute CLIP-Seq and Degradome-Seq data. Nucleic Acids Res 2011; 39(Database issue):D202-9; PMID:21037263; http:// dx.doi.org/10.1093/nar/gkq1056

38. Backman TW, Sullivan CM, Cumbie JS, Miller ZA, Chapman EJ, Fahlgren N, et al. Update of ASRP: the Arabidopsis Small RNA Project database. Nucleic Acids Res 2008; 36(Database issue):D982-5; PMID:17999994; http://dx.doi.org/10.1093/nar/gkm997

39. Molnár A, Schwach F, Studholme DJ, Thuenemann EC, Baulcombe DC. miRNAs control gene expression in the single-cell alga Chlamydomonas reinhardtii. Nature 2007; 447:1126-9; PMID:17538623; http:// dx.doi.org/10.1038/nature05903

40. Fei Z, Joung JG, Tang X, Zheng Y, Huang M, Lee JM, et al. Tomato Functional Genomics Database: a comprehensive resource and analysis package for tomato functional genomics. Nucleic Acids Res 2011; 39 (Database issue):D1156-63; PMID:20965973; http:// dx.doi.org/10.1093/nar/gkq991

41. Guttman M, Amit I, Garber M, French C, Lin MF, Feldser D, et al. Chromatin signature reveals over a thousand highly conserved large non-coding RNAs in mammals. Nature 2009; 458:223-7; PMID:19182780; http://dx.doi.org/10.1038/nature07672
42. Huarte M, Rinn JL. Large non-coding RNAs: missing links in cancer? Hum Mol Genet 2010; 19(R2):R15261; PMID:20729297; http://dx.doi.org/10.1093/hmg/ ddq353

43. Gibb EA, Brown CJ, Lam WL. The functional role of long non-coding RNA in human carcinomas. Mol Cancer 2011; 10:38; PMID:21489289; http://dx.doi. org/10.1186/1476-4598-10-38

44. Prensner JR, Chinnaiyan AM. The emergence of lncRNAs in cancer biology. Cancer Discov 2011; 1:391-407; PMID:22096659; http://dx.doi.org/10. 1158/2159-8290.CD-11-0209

45. Reis EM, Nakaya HI, Louro R, Canavez FC, Flatschart AV, Almeida GT, et al. Antisense intronic non-coding RNA levels correlate to the degree of tumor differentiation in prostate cancer. Oncogene 2004; 23:6684 92; PMID:15221013; http://dx.doi.org/10.1038/sj. onc. 1207880

46. Reis EM, Ojopi EP, Alberto FL, Rahal P, Tsukumo F, Mancini UM, et al. Head and Neck Annotation Consortium. Large-scale transcriptome analyses reveal new genetic marker candidates of head, neck, and thyroid cancer. Cancer Res 2005; 65:1693-9; PMID: 15753364; http://dx.doi.org/10.1158/0008-5472.CAN04-3506

47. Brito GC, Fachel AA, Vettore AL, Vignal GM, Gimba ER, Campos FS, et al. Identification of protein-coding and intronic noncoding RNAs down-regulated in clear cell renal carcinoma. Mol Carcinog 2008; 47:757-67; PMID:18348187; http://dx.doi.org/10.1002/mc.20433

48. Perez DS, Hoage TR, Pritchett JR, Ducharme-Smith AL, Halling ML, Ganapathiraju SC, et al. Long, abundantly expressed non-coding transcripts are altered in cancer. Hum Mol Genet 2008; 17:642-55; PMID: 18006640; http://dx.doi.org/10.1093/hmg/ddm336

49. Tahira AC, Kubrusly MS, Faria MF, Dazzani B, Fonseca RS, Maracaja-Coutinho V, et al. Long noncoding intronic RNAs are differentially expressed in primary and metastatic pancreatic cancer. Mol Cancer 2011; 10:141; PMID:22078386; http://dx.doi.org/10. 1186/1476-4598-10-141

50. Mercer TR, Gerhardt DJ, Dinger ME, Crawford J, Trapnell C, Jeddeloh JA, et al. Targeted RNA sequencing reveals the deep complexity of the human transcriptome. Nat Biotechnol 2012; 30:99-104 PMID:22081020; http://dx.doi.org/10.1038/nbt.2024

51. Kapranov P, Drenkow J, Cheng J, Long J, Helt G, Dike $S$, et al. Examples of the complex architecture of the human transcriptome revealed by RACE and high-density tiling arrays. Genome Res 2005; 15:987-97; PMID: 15998911; http://dx.doi.org/10.1101/gr.3455305

52. Kapranov P, St Laurent G, Raz T, Ozsolak F, Reynolds $\mathrm{CP}$, Sorensen PH, et al. The majority of total nuclearencoded non-ribosomal RNA in a human cell is 'dark matter' un-annotated RNA. BMC Biol 2010; 8:149; PMID:21176148; http://dx.doi.org/10.1186/17417007-8-149

53. Cao Y, Wu J, Liu Q, Zhao Y, Ying X, Cha L, et al. sRNATarBase: a comprehensive database of bacterial sRNA targets verified by experiments. RNA 2010; 16 : 2051-7; PMID:20843985; http://dx.doi.org/10.1261/ rna. 2193110

54. Tamura M, Hendrix DK, Klosterman PS, Schimmelman NR, Brenner SE, Holbrook SR, Sr. SCOR: Structural Classification of RNA, version 2.0. Nucleic Acids Res 2004; 32(Database issue):D182-4; PMID:14681389; http://dx.doi.org/10.1093/nar/gkh080

55. Turner DH, Mathews DH. NNDB: the nearest neighbor parameter database for predicting stability of nucleic acid secondary structure. Nucleic Acids Res 2010; 38(Database issue):D280-2; PMID:19880381; http://dx.doi.org/10.1093/nar/gkp892
56. Tacutu R, Budovsky A, Fraifeld VE. The NetAge database: a compendium of networks for longevity, agerelated diseases and associated processes. Biogerontology 2010; 11:513-22; PMID:20186480; http://dx.doi. org/10.1007/s10522-010-9265-8

57. Wu T, Wang J, Liu C, Zhang Y, Shi B, Zhu X, et al. NPInter: the noncoding RNAs and protein related biomacromolecules interaction database. Nucleic Acids Res 2006; 34(Database issue):D150-2; PMID:16381834; http://dx.doi.org/10.1093/nar/gkj025

58. Xiao F, Zuo Z, Cai G, Kang S, Gao X, Li T. miRecords: an integrated resource for microRNA-target interactions. Nucleic Acids Res 2009; 37(Database issue):D105-10; PMID:18996891; http://dx.doi.org/ 10.1093/nar/gkn851

59. Piekna-Przybylska D, Decatur WA, Fournier MJ. New bioinformatic tools for analysis of nucleotide modifications in eukaryotic rRNA. RNA 2007; 13:30512; PMID:17283215; http://dx.doi.org/10.1261/rna. 373107

60. Xin Y, Olson WK. BPS: a database of RNA base-pair structures. Nucleic Acids Res 2009; 37(Database issue): D83-8; PMID:18845572; http://dx.doi.org/10.1093/ nar/gkn676

61. Nagaswamy U, Larios-Sanz M, Hury J, Collins S, Zhang Z, Zhao Q, et al. NCIR: a database of noncanonical interactions in known RNA structures. Nucleic Acids Res 2002; 30:395-7; PMID:11752347; http://dx.doi.org/10.1093/nar/30.1.395

62. Birney E, Stamatoyannopoulos JA, Dutta A, Guigó R, Gingeras TR, Margulies EH, et al, ENCODE Project Consortium, NISC Comparative Sequencing Program, Baylor College of Medicine Human Genome Sequencing Center, Washington University Genome Sequencing Center, Broad Institute, Children's Hospital Oakland Research Institute. Identification and analysis of functional elements in $1 \%$ of the human genome by the ENCODE pilot project. Nature 2007; 447:799-816; PMID:17571346; http://dx.doi. org/10.1038/nature05874

63. Amaral PP, Mattick JS. Noncoding RNA in development. Mamm Genome 2008; 19:454-92; PMID: 18839252; http://dx.doi.org/10.1007/s00335-0089136-7

64. Seidl CI, Stricker SH, Barlow DP. The imprinted Air ncRNA is an atypical RNAPII transcript that evades splicing and escapes nuclear export. EMBO J 2006; 25:3565-75; PMID:16874305; http://dx.doi.org/10. 1038/sj.emboj.7601245

65. Tripathi V, Ellis JD, Shen Z, Song DY, Pan Q, Watt AT, et al. The nuclear-retained noncoding RNA MALAT1 regulates alternative splicing by modulating SR splicing factor phosphorylation. Mol Cell 2010; 39:925-38; PMID:20797886; http://dx.doi.org/10. 1016/j.molcel.2010.08.011

66. Rinn JL, Kertesz M, Wang JK, Squazzo SL, Xu X, Brugmann SA, et al. Functional demarcation of active and silent chromatin domains in human HOX loci by noncoding RNAs. Cell 2007; 129:1311-23; PMID: 17604720; http://dx.doi.org/10.1016/j.cell.2007.05.022

67. Tsai MC, Manor O, Wan Y, Mosammaparast N, Wang JK, Lan F, et al. Long noncoding RNA as modular scaffold of histone modification complexes. Science 2010; 329:689-93; PMID:20616235; http://dx.doi. org/10.1126/science. 1192002

68. Huarte M, Guttman M, Feldser D, Garber M, Koziol MJ, Kenzelmann-Broz D, et al. A large intergenic noncoding RNA induced by p 53 mediates global gene repression in the p53 response. Cell 2010; 142:409-19; PMID:20673990; http://dx.doi.org/10.1016/j.cell.2010. 06.040 
69. Wang H, Iacoangeli A, Popp S, Muslimov IA, Imataka $\mathrm{H}$, Sonenberg N, et al. Dendritic BC1 RNA: functional role in regulation of translation initiation. J Neurosci 2002; 22:10232-41; PMID:12451124

70. Wang KC, Chang HY. Molecular mechanisms of long noncoding RNAs. Mol Cell 2011; 43:904-14; PMID: 21925379; http://dx.doi.org/10.1016/j.molcel.2011. 08.018

71. Cho S, Jun Y, Lee S, Choi HS, Jung S, Jang Y, et al. miRGator v2.0: an integrated system for functional investigation of microRNAs. Nucleic Acids Res 2011; 39(Database issue):D158-62; PMID:21062822; http:// dx.doi.org/10.1093/nar/gkq1094

72. Huang HY, Chang HY, Chou CH, Tseng CP, Ho SY, Yang CD, et al. sRNAMap: genomic maps for small non-coding RNAs, their regulators and their targets in microbial genomes. Nucleic Acids Res 2009; 37 (Database issue):D150-4; PMID:19015153; http://dx. doi.org/10.1093/nar/gkn852
73. Wang X. miRDB: a microRNA target prediction and functional annotation database with a wiki interface. RNA 2008; 14:1012-7; PMID:18426918; http://dx. doi.org/10.1261/rna.965408

74. Bandyopadhyay S, Bhattacharyya M. PuTmiR: a database for extracting neighboring transcription factors of human microRNAs. BMC Bioinformatics 2010; 11:190; PMID:20398296; http://dx.doi.org/10.1186/ 1471-2105-11-190

75. Friard O, Re A, Taverna D, De Bortoli M, Corá D CircuitsDB: a database of mixed microRNA/transcription factor feed-forward regulatory circuits in human and mouse. BMC Bioinformatics 2010; 11:435 PMID:20731828; http://dx.doi.org/10.1186/14712105-11-435

76. Chiromatzo AO, Oliveira TY, Pereira G, Costa AY, Montesco CA, Gras DE, et al. miRNApath: a database of miRNAs, target genes and metabolic pathways. Genet Mol Res 2007; 6:859-65; PMID:18058708
77. Schmeier S, Schaefer U, MacPherson CR, Bajic VB. dPORE-miRNA: polymorphic regulation of microRNA genes. PLoS One 2011; 6:e16657; PMID:21326606; http://dx.doi.org/10.1371/journal.pone.0016657

78. Hsu SD, Lin FM, Wu WY, Liang C, Huang WC Chan WL, et al. miRTarBase: a database curates experimentally validated microRNA-target interactions. Nucleic Acids Res 2011; 39(Database issue): D163-9; PMID:21071411; http://dx.doi.org/10.1093/ nar/gkq1107

79. Altschul SF, Gish W, Miller W, Myers EW, Lipman DJ. Basic local alignment search tool. J Mol Biol 1990; 215:403-10; PMID:2231712

80. Torarinsson E, Sawera M, Havgaard JH, Fredholm M, Gorodkin J. Thousands of corresponding human and mouse genomic regions unalignable in primary sequence contain common RNA structure. Genom Res 2006; 16:885-9; PMID:16751343; http://dx.doi. org/10.1101/gr.5226606
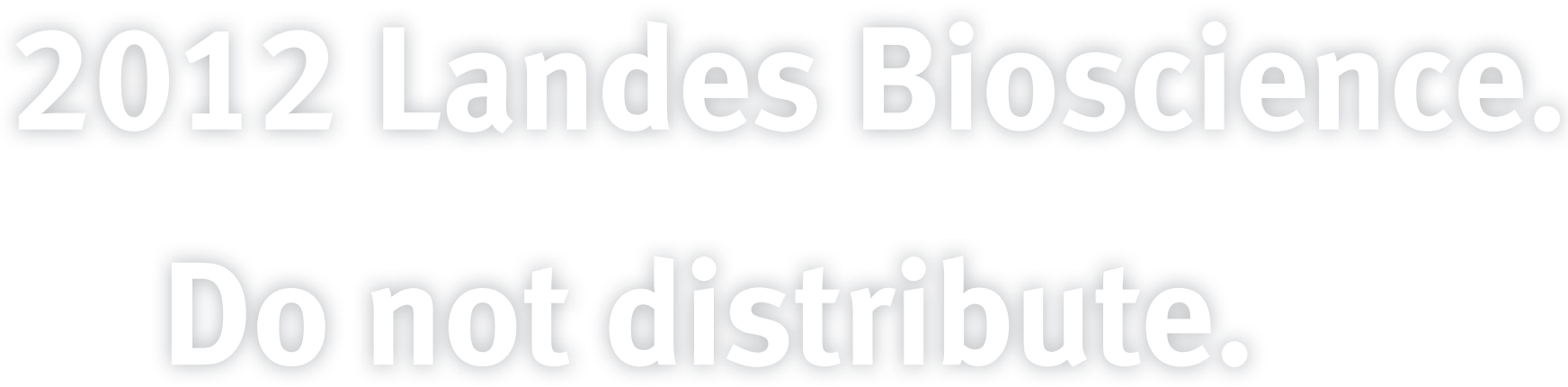